\title{
Mechanical behaviour of concrete piles affected by sulphate attack
}

\author{
Dr. Mathias Flansbjer \\ SP Technical Research \\ Institute of Sweden \\ Box 857, SE 50115 Borås \\ mathias.flansbjer@sp.se
}

\author{
Dr. Jan Erik Lindqvist \\ janerik.lindqvist@cbi.se \\ Dr. Kamyab Zandi Hanjari \\ kamyab.zandi@cbi.se \\ CBI Swedish Cement and \\ Concrete Research Institute \\ Box 857, SE 50115 Borås \\ Gabriel Johansson \\ CBI Swedish Cement and \\ Concrete Research Institute \\ Box 118, 22100 Lund \\ gabriel.johansson@cbi.se
}

Michael Löfgren

Port of Göteborg

SE 40338 Göteborg

michael.lofgren@portgot.se

\begin{abstract}
Assessing the remaining service life is vital for the planning of maintenance of concrete constructions in aggressive environments. Here we present results from testing of two concrete piles affected by sulphate attack in marine environment. A multi method approach going from micro scale to structural level has been applied. The crack propagation was monitored during loading by means of Digital Image Correlation (DIC) and Acoustic Emission (AE). After the test cracks were studied using fluorescence microscopy. Furthermore, finite element analysis was used to study the influence of the chemical attack on the response of the piles.
\end{abstract}

Key words: Marine constructions, mechanical testing, finite element analysis, microscopic analysis, Digital Image Correlation, Acoustic Emission.

\section{INTRODUCTION}

This paper concerns with two concrete piles damaged by external sulphate attack to different degrees. The piles have been exposed to the marine environment for about 40 years. Both piles have the dimension of $320 \times 320 \mathrm{~mm}$ in cross section and were cut to a length of $900 \mathrm{~mm}$. The less damaged pile and the severely damaged pile are denoted Pile A and Pile B, respectively. External sulphate attack is characterized by formation of ettringite and a reduction of $\mathrm{Ca}^{2+}$ in the calcium silica ( $\mathrm{CSH}-)$ gel that forms the cement paste. This attack results in expansion which leads to crack formation. These occur parallel to the exposed surface and open adhesion cracks surrounding the aggregate particles. In an advance stage, cracks may form in the cement paste connecting different adhesion cracks.

Three-dimensional non-linear finite element analysis (FEA) at the structural level has proved to be capable of describing the behaviour of reinforced concrete in a comprehensive way, provided that appropriate constitutive models are adapted. Although detailed structural analyses are numerically expensive, they allow for a better description of the behaviour at both the material and structural levels. This type of analysis has been used here to study the behaviour of the concrete piles. The influence of damage was taken into account by adapting material properties; a similar methodology has been applied by other researchers to study the structural behaviour of corroded structures /Coronelli 2004/ and frost-damaged structures /Zandi Hanjari 2011/. The results from numerical analysis were verified with the results from mechanical testing with respect to global behaviour and load-carrying capacity.

\section{MECHANICAL TESTING}

\subsection{Material testing}

The concrete properties of the two piles (A and B) were determined by tests on core-drilled cylinders, see Table 1 . The tensile strength, $f_{\mathrm{ct}}$, and fracture energy, $G_{\mathrm{F}}$, were obtained from direct tensile tests, performed on notched cylinders $(\varnothing 100 \times 100 \mathrm{~mm})$ with fixed end-conditions following the recommendations in /RILEM TC 187-SOC/. The Young's modulus, $E_{0}$, and compressive strength, $f_{\mathrm{cc}}$, were obtained by compression tests on cylinders $(\varnothing 100 \times 200 \mathrm{~mm})$. 
Table 1 - Summary of concrete material properties (mean values and standard deviations).

\begin{tabular}{ccccc}
\hline Pile & $\begin{array}{c}E_{0} \\
{[\mathrm{GPa}]}\end{array}$ & $\begin{array}{c}f_{\mathrm{cc}} \\
{[\mathrm{MPa}]}\end{array}$ & $\begin{array}{c}f_{\mathrm{ct}} \\
{[\mathrm{MPa}]}\end{array}$ & $\begin{array}{c}G_{\mathrm{F}} \\
{[\mathrm{N} / \mathrm{m}]}\end{array}$ \\
\hline A & $29.7(2.2)$ & $52.3(2.1)$ & $3.2(0.4)$ & $187(32)$ \\
B & $21.6(1.5)$ & $42.5(3.8)$ & $2.7(0.5)$ & $163(22)$ \\
\hline
\end{tabular}

During the compression tests the full-field deformation field was monitored at the surface of the cylinders by means of DIC. The deformation field was used to quantify how the damage to the concrete changes with distance from the exposed surface by analyzing the stiffness degradation in segments along cored concrete cylinders. This method was first used in a study of assessment of concrete structures after fire and is described in /Albrektsson et al. 2011/. The results show that in Pile B the stiffness in concrete cover area is about 30-50\% lower compared with the core area inside the reinforcement, while in Pile A the concrete cover area is instead $30-50 \%$ stiffer compared with the core area. The cracking process during the compression tests was also recorded by two AE-sensors. The specimens from Pile A show significantly more AE-activity compared with the specimens from Pile B.

\subsection{Pile testing}

The compression tests of the stub pile specimens $(h 900 \mathrm{~mm})$ were carried out in a test machine with a maximum load capacity of $20 \mathrm{MN}$, see Figure 1(a). The tests were conducted using moment stiff loading plates. The tests were carried out under displacement control with a rate of $0.3 \mathrm{~mm} / \mathrm{min}$. The cracking process, monitored at one side of the specimen during the loading by means of DIC and the AE activity, was also recorded by a total of six AE-sensors.

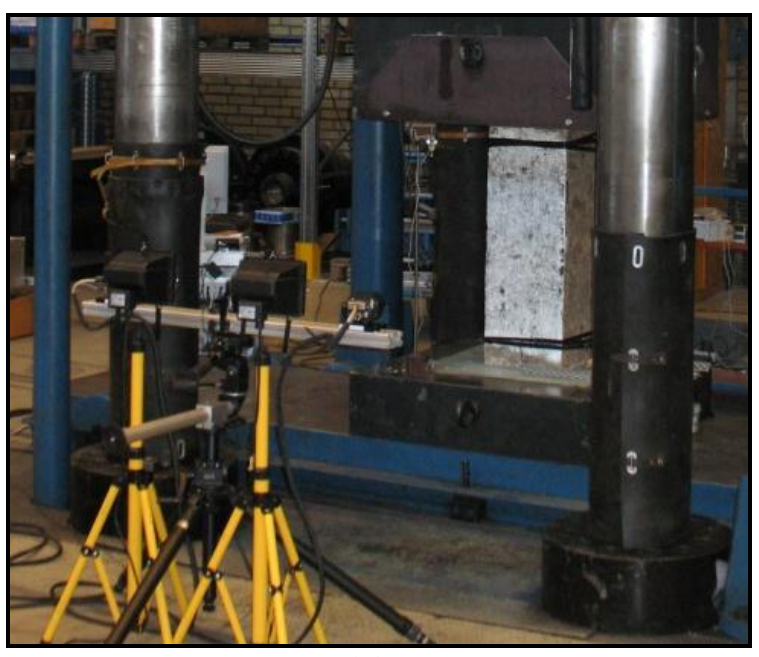

(a)

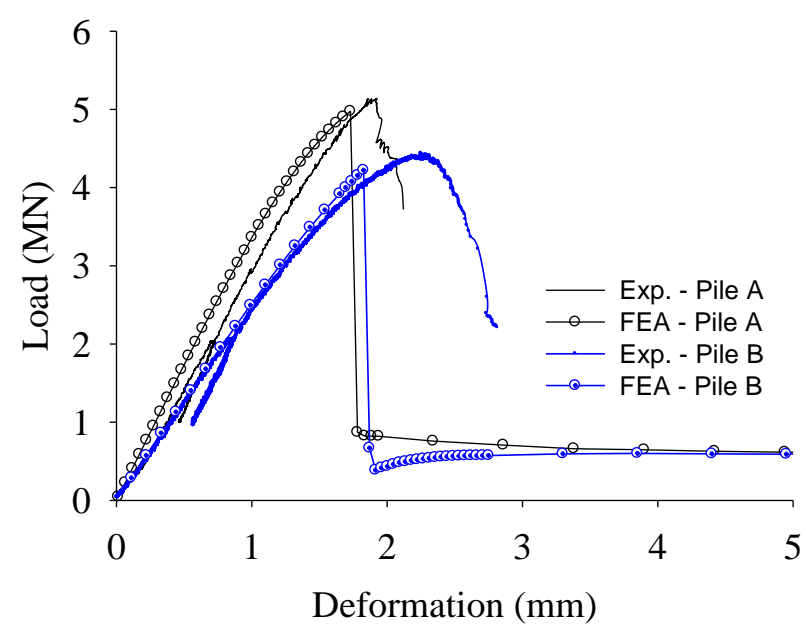

(b)

Fig. 1 (a) Photo of the test set-up of the piles with the DIC system showing in the foreground and (b) results from compression tests on concrete Pile A and B together with results from FE analysis.

The load-displacement relations from the compression test on the piles are presented in Figure 1(b). Pile A exhibits a higher stiffness, a relatively linear behaviour in pre-peak response and a higher capacity compared to Pile B. Cracks were observed earlier by the DIC measurements for Pile B compared with Pile A; this explains the stiffness loss observed in Pile B in the pre-peak response. For Pile B, the crack formations were mainly located to preexisting vertical cracks along the reinforcement. In both cases the final failure was caused by vertical cracks due to spalling of the concrete cover. The maximum load capacity was $5.14 \mathrm{MN}$ and 4.44 MN for Pile A and Pile B, respectively. As in the compression tests on the cores, the 
AE activity was significantly higher for Pile A compared with Pile $B$, both in number of hits and absolute energy.

\section{ANALYSIS OF CRACK PATTERNS IN THE CROSS SECTIONS}

Samples were diamond sawed from the piles for micro structural analysis before and after the test. Plane polished samples with an area covering about $2 / 3$ of the cross section of the pile were produced. These samples were impregnated with fluorescent epoxy dye which made it possible to identify cracks from micro scale and upwards. Thin sections for microscopic analysis were made in addition. The aim was to investigate how the crack pattern in the tested beams were related to pre-existing cracks, reinforcement, aggregate particles and the damage pattern from the sulfate attack. This information was then used for verification of the numerical model.

The severely damaged pile (Pile B) showed a complex zonal porosity pattern with several layers of centimeter thickness with the difference in the porosity of the cement paste into a depth of about $60 \mathrm{~mm}$ from the surface. The main crack patterns of this pile were cracks radiating from the reinforcement bars and going out to the surface but also diagonally through the center of the pile. There were also some surface parallel cracks in the outermost layers. Open adhesion cracks were less frequent in this pile. Ettringite filled cracks especially in the contacts to the aggregate particles were frequent. After testing, pre-existing diagonal cracks had further developed and a shear crack had propagated between the reinforcement bars parallel to one side. The cracks mainly passed the aggregate particles in the Interfacial Transition Zone (ITZ). The number of cracks formed during testing was much lower in this pile than that in the less damaged pile.

The less damaged pile (Pile A) showed a less complex zonal pattern of the cement paste porosity than the severely damaged pile. The cement paste was less porous outside the reinforcement. The crack frequency of the sample before testing was high from the surface to the center. There were longer cracks, about $5 \mathrm{~cm}$, radiating out from the reinforcement bars. The main cracks were centimeters to decimeters long going diagonally. There were also micro cracks with a length of a few millimeters up to a centimeter. Adhesion cracks in the aggregate contacts were frequent; however, ettringite filled cracks were not. The main cracks, formed during testing, were a system of cracks connecting the reinforcement bars going adjacent to the stirrups and also cracks going from the bars to the surface of the pile. The ITZ had mostly open cracks after the test but the cracks, to a large extent, had also propagated through the aggregate particles.

\section{NUMERICAL MODELLING}

Three-dimensional non-linear finite element analysis at the structural level has been used to study the mechanical behaviour of the concrete piles under compression. As the reinforcement arrangements in the piles were not symmetric, the entire piles were included in the FE model. Concrete was modelled with three-dimensional pentahedron solid elements with a side length of $20 \mathrm{~mm}$. A constitutive model based on non-linear fracture mechanics, with a smeared rotating crack model based on total strain, was applied /DIANA 2009/. The crack band width was assumed to be equal to the element size; this was later verified to be a good approximation of the localization zone in the analyses. The longitudinal bars and stirrups were embedded in the concrete elements, corresponding to a perfect bond between the rebar and concrete.

The material properties of concrete which were determined through compression test and direct tensile test were used in the analysis; see Table 1. For concrete in compression, the stress-strain relation given by /Thorenfeldt et al. 1991/ was adapted for Pile A; this was a good estimation of the stress-strain curve observed in the compression test. However, an average experimental 
stress-strain relation from compression test had to be used for Pile B. This was because Pile B was severely damaged by sulphate attack and the relation given in /Thorenfeldt et al. 1991/ was no longer a good representation. For concrete in tension, the softening behaviour given by /Hordijk 1987/ was adapted for both piles. Since no test was carried out on steel bars, the reinforcement was modelled as elasto-plastic. The yield and ultimate stresses were assumed to be $f_{s y}=400 \mathrm{MPa}$ and $f_{s u}=500 \mathrm{MPa}$ and the elastic modulus was assumed to be $E_{s 0}=200 \mathrm{GPa}$.

The results from numerical analyses and experiments are presented in Figure 1(b). The analyses, similar to that observed in the experiments, show large stiffness degradation and approx. $15 \%$ reduction in the load-carrying capacity as the result of sulphate attack. Yielding of stirrups at a load level of about 2.5 MN caused several cracks in Pile B. However, the crack pattern was different from that observed in the experiment. This was because the crack pattern in pile B was highly influenced by the pre-existing cracks; while these cracks were not included in the analysis. A better agreement between experimental and numerical crack patterns was seen in the case of Pile A. The failure of both piles was triggered by yielding of one longitudinal bar, with least concrete cover, preceded by crushing of concrete. The analysis carried out in this study showed to be capable of describing the global behaviour of both piles, and reasonably estimating the stiffness degradation and capacity reduction due to sulphate attack.

\section{CONCLUSIONS}

The paper investigated the mechanical behaviour of concrete piles affected by sulphate attack. This was done by combining (a) material and structural testing, (b) DIC and AE, (c) microscopical analysis, and (d) numerical analysis. The global behaviour of the piles was largely influence by the damage; this was seen both in the experiment and FE analysis. However, the failure modes at the global level remained relatively the same. More significant influence was observed on the crack pattern which was studied through fluorescence microscopy and DIC. The crack formation in the severely damaged pile was mainly located to pre-existing cracks. More detailed study of the AE results however remains for the future work.

\section{REFERENCES}

Albrektsson, J., Flansbjer, M., Lindqvist, JE. \& Jansson, R., 2011, ”Assessment of concrete structures after fire", SP report 2011:19, March 2011.

Coronelli, D., \& Gambarova, P., 2004, "Structural assessment of corroded reinforced concrete beams: Modeling guidelines", Journal of Structural Engineering, Vol. 130, No. 8, pp. 1214-1224.

DIANA, 2009, "DIANA Finite Element Analysis, User's Manual, release 9.3. TNO Building and Construction Research", Delft, Netherlands.

Flansbjer, M., Lindqvist, JE. \& Silfwerbrand, J., 2011, "Quantitative fracture characteristics in shear load", Fib Symposium, Prague, 12pp.

Hordijk, D. A., 1991, "Local Approach to Fatigue of Concrete”, Doctoral thesis, Delft University of Technology, Delft, Netherlands.

RILEM TC 187-SOC, 2007, "Experimental determination of the stress-crack opening curve for concrete in tension", Final report, May 2007.

Thorenfeldt, E., Tomaszewicz, A. \& Jensen, J. J., 1987, “Mechanical properties of high-strength concrete and applications in design", Conference on Utilization of High-Strength Concrete, Stavanger, Norway.

Zandi Hanjari, K., Kettil, P. \& Lundgren, K., 2011, "Modelling the structural behaviour of frostdamaged reinforced concrete structures", Structure and Infrastructure Engineering, DOI:10.1080/15732479.2011.552916. 